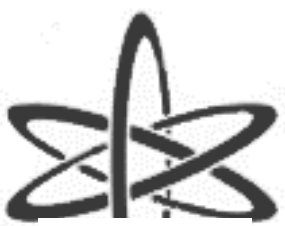

BJRS
BRAZILIAN JOURNAL

$\mathrm{OF}$

RADIATION SCIENCES

05-01 (2017) 01-07

\title{
Method to evaluate the L/D Ratio of Neutron Imaging Beams
}

\author{
R. Pugliesi; M. A. Stanojev Pereira; R. M. Schoueri \\ Instituto de Pesquisas Energéticas e Nucleares IPEN-CNEN/SP. Av. Prof. Lineu Prestes 2242, Butantã, Cidade \\ Universitária, CEP 05508 000, São Paulo - SP, Brasil \\ pugliesi@ipen.br
}

\begin{abstract}
An alternative simple method to evaluate the L/D ratio of neutron imaging beams is proposed. It is based on the behavior of the ratio " $\mathrm{x} / \mathrm{Ut}$ ", which asymptotically tends to L/D for large values of the parameter " $\mathrm{x}$ ", that corresponds to the distance separating a gadolinium test object to the scintillator plane, where its image is formed. The method was applied to the neutron imaging equipment of the Nuclear and Energy Research Institute IPENCNEN/SP and the obtained result was $L / D=(104 \pm 4)$. The consistency of the proposed method was verified by comparing this value with those ones obtained by a well - known and established procedure.
\end{abstract}

Keywords: neutron imaging, neutron tomography, L/D ratio.

\section{INTRODUCTION}

Neutron imaging techniques make use of neutron as penetrating radiation to investigate the internal structure of objects. In a typical equipment, the image is formed in a scintillator and is captured by a digital video camera. The spatial resolution is an important parameter to characterize the image quality and usually is quoted in terms of the total unsharpness (Ut), consisting of two components: the intrinsic unsharpness (Ui) which depends of the, scintillator 
and camera features, such as chemical composition, thickness, pixel size, focusing condition, among others; the geometrical unsharpness (Ug) from the angular divergence of the beam, characterized by the $\mathrm{L} / \mathrm{D}$ ratio, where $\mathrm{L}$ is the distance between the entrance aperture of the beam to the image plane, and $\mathrm{D}$ the diameter of the beam aperture [1,2]. The combined effect of both is responsible for the blurring in the image, they are related by formula (1), and the exponent " $n$ " depends of the ratio $\mathrm{Ug} / \mathrm{Ui}[3,4]$.

$$
U t^{n}=U i^{n}+U g^{n}
$$

This paper proposes a simple method to evaluate the L/D ratio of neutron beams for imaging purposes. From literature, $L / D$ is given by formula (2), where " $x$ " is the distance from the object to the scintillator plane. In the proposed method, L/D is determined from the asymptotic behavior of relation (3) as a function of " $\mathrm{x}$ ", in the limit of large distances. This can be justified because, the larger the value of " $\mathrm{x}$ " the larger is Ug, and according to (1), for Ui constant, Ut tends to Ug, and therefore $\mathrm{x} / \mathrm{Ut}$ tends to $\mathrm{L} / \mathrm{D}$.

$$
\begin{aligned}
& L / D=x / U g \\
& L / D=x / U t
\end{aligned}
$$

\section{EXPERIMENTAL}

The method was applied to the equipment for neutron imaging of the Nuclear and Energy Research Institute IPEN-CNEN/SP, which is installed at the pool type IEA-R1 Nuclear Research Reactor [5,6]. Some of its main characteristics are showed in Table 1.

Table 1: Characteristics of the neutron imaging equipment.

\begin{tabular}{cc}
\hline Neutron flux at the test object & $8 \times 10^{6} \mathrm{n} \cdot \mathrm{s}^{-1} \cdot \mathrm{cm}^{-2}$ \\
\hline Scintillator & ${ }^{6} \mathrm{LiF}(\mathrm{ZnS}) 18 \times 24 \mathrm{~cm}$, thickness $250 \mu \mathrm{m}$ \\
\hline Beam diameter & $15 \mathrm{~cm}$ \\
\hline Mean energy of the beam & $7 \mathrm{meV}$ \\
\hline Digital video camera & ANDOR ikon - M cooled CCD \\
& $(1024 \times 1024$, pixel size $13 \mu \mathrm{m})$ \\
\hline
\end{tabular}


In order to determine the values of Ut, a knife - edge test object (gadolinium sheet $1 \mathrm{~cm} \mathrm{x} 2 \mathrm{~cm} \mathrm{x}$ $127 \mu \mathrm{m}$ ) was fixed in a sample holder, manufactured in aluminum, which can precisely position it, to distances $7000 \leq \mathrm{x} \leq 102000 \mu \mathrm{m}$ with respect to the scintillator plane, to be irradiated. For each distance, one image of the test object is captured by a digital video camera, in an exposure time of $1 \mathrm{~s}$, the one for which the best dynamic range is achieved [6]. The boundary region between this image and the one corresponding to the direct neutron beam was scanned by means of a software line profile tool, which provides a gray level (GL) intensity distribution as a function of the scanning coordinate. To each resulting distribution, the Edge Spread Function (4), was fitted and the value of Ut was evaluated by (5) [4,5,7].

$$
G L=p 1+p 2 \cdot \operatorname{atan}(p 3 \cdot(l-p 4))
$$

where $\mathrm{p}_{1}, \mathrm{p}_{2}, \mathrm{p}_{3}$ and $\mathrm{p}_{4}$ are free parameters and $\quad \mathrm{l}$ is the scanning coordinate

$$
U t=2 / p 3
$$

\section{RESULTS AND DISCUSSION}

The Figure 1 shows a typical obtained distribution, the fitted function (4) and the fitting parameters, for the image of the test object irradiated at the distance $52000 \mu \mathrm{m}$. 
Figure 1: Typical distribution and the fitting for the distance $52000 \mu \mathrm{m}$.

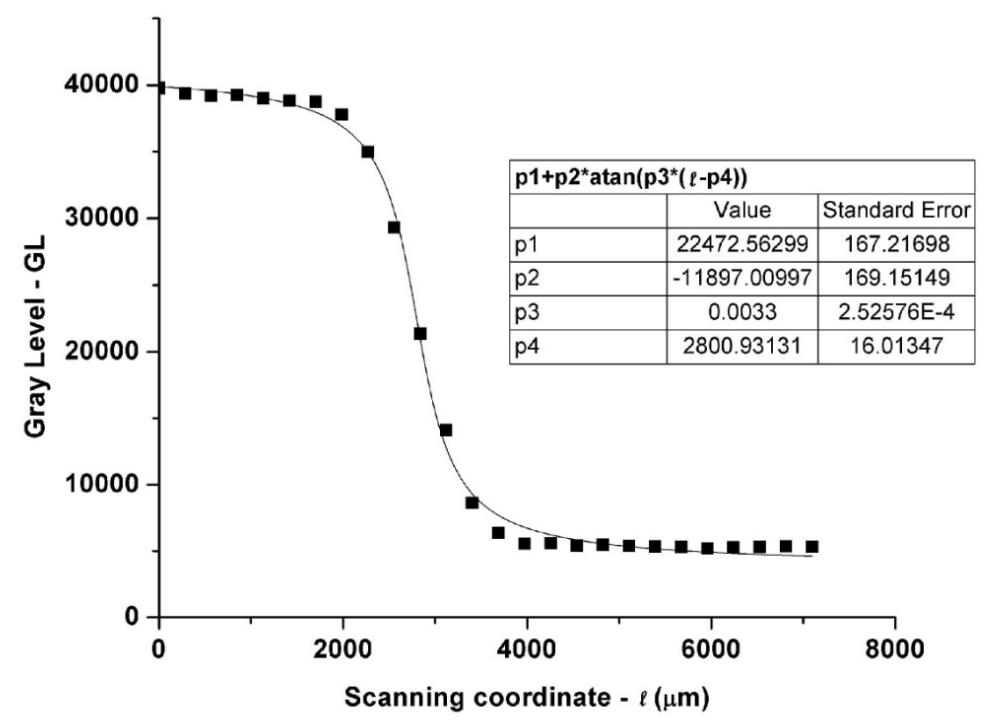

The obtained values for Ut and the behavior of ratio " $\mathrm{x} / \mathrm{Ut}$ " as a function of the distances " $\mathrm{x}$ " from the scintillator plane are showed in the Table 2 and in the Fig. 2 respectively.

Table 2: Values for Ut as a function of the test object to scitillator plane distance " $x$ ”.

\begin{tabular}{cccc}
\hline $\mathbf{x}(\boldsymbol{\mu} \mathbf{m})$ & $\mathbf{U t}(\boldsymbol{\mu m})$ & $\mathbf{x}(\boldsymbol{\mu m})$ & $\mathbf{U t}(\boldsymbol{\mu m})$ \\
\hline 7000 & $410 \pm 29$ & 52000 & $606 \pm 46$ \\
12000 & $424 \pm 29$ & 62000 & $667 \pm 51$ \\
22000 & $439 \pm 34$ & 82000 & $862 \pm 74$ \\
32000 & $512 \pm 38$ & 102000 & $1064 \pm 74$ \\
42000 & $522 \pm 39$ & $/ / / / / / / / / / /$ & $/ / / / / / / / / / / / / /$ \\
\hline
\end{tabular}

The exponential function (6) was fitted to the experimental data, and as can be seen in the Fig. 2, the larger the distance " $\mathrm{x}$ ”, the larger the ratio “x/Ut”. Above $\sim 60000 \mu \mathrm{m}$ the ratio increases more slowly and in the limit of large distances, as already mentioned above, asymptotically tends to L/D. Numerically it is given by the parameter “y0" of the fitted function, resulting L/D = (104 $\pm 4)$.

$$
y=A 1 * e^{-x / t 1}+y 0
$$


Figure 2: Behavior of the ratio " $\mathrm{x} / \mathrm{Ut}$ " as a function of the object to scintillator plane distance " $x$ ".

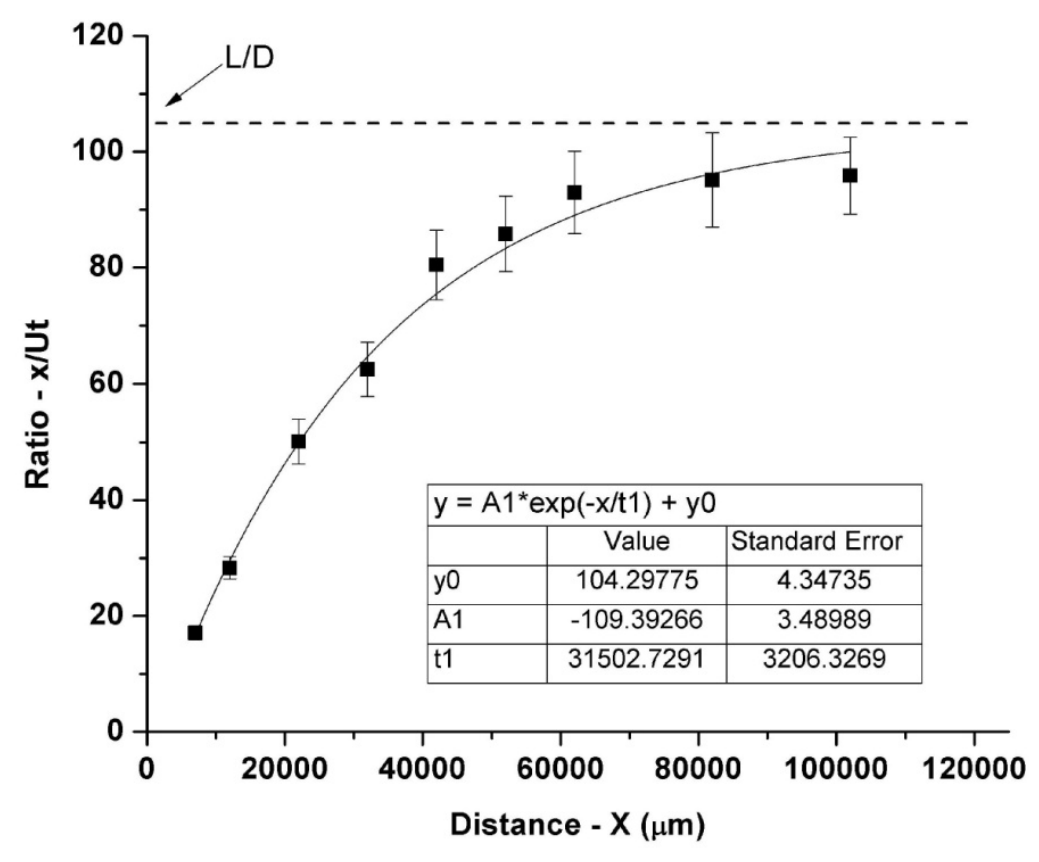

The consistency of the proposed method was checked by comparing the obtained value for L/D with those ones determined by a well - known and established procedure [3, 4]. In such a case (1) is employed, taking into account the selection rule deduced by Harms, in which the value of the index " $\mathrm{n}$ " is determined by the ratio $\mathrm{Ug} / \mathrm{Ui}$. According to this rule the following pair of values (n , Ug/Ui), are valid: (1.3 , 10), (1.4 , 3.5), (1.5 , 2.5), (1.6 , 0.7), (1.7, 0.5) and (1.8 , 0.1 ). The procedure to determinate $\mathrm{L} / \mathrm{D}$ is the following: calculate the ratios $\mathrm{Ug} / \mathrm{Ui}$ using (1), as a function, of " $\mathrm{n}$ " [3] and of Ut in Table 2, considering for the present imaging facility, Ui = (205 \pm 24) $\mu \mathrm{m}[6]$; compare the obtained pair of values ( $\mathrm{n}, \mathrm{Ug} / \mathrm{Ui}$ ) to the ones mentioned above, to determine which them are valid; the Table 3 shows the valid pairs, the distances " $x$ " they were calculated, the values of $\mathrm{Ug}$ evaluated from the respective ratios $\mathrm{Ug} / \mathrm{Ui}$, and the $\mathrm{L} / \mathrm{D}$ ratios, determined using (2). 
Table 3: Summary of the obtained results for n, Ug, “ $x$ ” and L/D. The uncertainties were evaluated by means of the standard propagation rules.

\begin{tabular}{cccc}
\hline $\mathbf{( n , ~ U g / U i )}$ & $\mathbf{x}(\boldsymbol{\mu} \mathbf{m})$ & $\mathbf{U g}$ & $\mathbf{L} / \mathbf{D}$ \\
\hline$(1.5,2.1 \pm 0.5)$ & 42000 & $(432 \pm 112)$ & $(97 \pm 25)$ \\
$(1.5,2.6 \pm 0.6)$ & 52000 & $(524 \pm 134)$ & $(99 \pm 25)$ \\
$(1.5,2.9 \pm 0.7)$ & 62000 & $(589 \pm 151)$ & $(105 \pm 27)$ \\
$(1.4,3.8 \pm 0.9)$ & 82000 & $(778 \pm 197)$ & $(105 \pm 27)$ \\
\hline
\end{tabular}

\section{CONCLUSIONS}

An alternative method to evaluating the L/D ratio of neutron imaging beams was proposed. It was applied to the neutron imaging facility of the IPEN-CNEN/SP, which is installed at the IEAR1 Nuclear Research Reactor resulting L/D = (104 \pm 4$)$. This result was compared with the four ones, obtained by an independent well - known and established procedure, showed in Table 3. As can be seen all the obtained results agree within their uncertainties, proving the consistency of the proposed method. Their main characteristics are its simplicity and accessibility, because besides it makes use of an ordinary test object, namely a small gadolinium sheet, it is a two parameters method, i.e., the total unsharpness (Ut) and the distance (x) of the test object to the scintillator plane.

\section{ACKNOWLEDGMENTS}

The authors are indebted to International Atomic Energy Agency - IAEA and to National Council of Technological and Scientific Development - CNPq (Brazil) for the partial financial support to this project through the grant CRP code F11018 and the Fellowship 114862/2015-0 respectively. 


\section{REFERENCES}

1. American Society for Testing and Materials. Determining the L/D ratio of neutron radiography beams: ASTM, (E803), 1981.

2. VON DER HARDT, P.; ROETTGER, H. Neutron Radiography Handbook: Nuclear Science and Technology. Dordrecht, D.Reidl, 1981.

3. HARMS, A. A.; ZEILINGER, A. A. New Formulation of Total Unsharpness in Radiograph, Phys. Med. Biol., v. 22, no 1, p. 70-80. 1977.

4. WADE, ,J. R.; HOWARD, A. L. Experiments at Argonne National Laboratory, Nucl. Technol., v. 76, no 3, p. 408-419, 1987.

5. STANOJEV PEREIRA, M. A.; SCHOUERI, R.; DOMIENIKAN, C.; TOLEDO, F.; ANDRADE, M. L. G.; PUGLIESI, R. The neutron tomography facility of IPENCNEN/SP and its potential to investigate ceramic objects from the Brazilian cultural heritage, Appl. Rad. and Isot., v. 75, p. 6-10, 2013.

6. SCHOUERI, R.; DOMIENIKAN, C.; TOLEDO, F.; ANDRADE, M. L. G.; STANOJEV PEREIRA, M. A.; PUGLIESI, R. The new facility for neutron tomography of IPENCNEN/SP and its potential to investigate hydrogenous substances, Appl. Rad. and Isot., v. 84, p. 22-26, 2014.

7. WROBEL, M.; GREIM, L. Resolution functions and unsharpness in neutron radiography. GKKS/e/12 $2^{\text {th }}$ ed. Geesthacht, Germany: GKKS, 1988. 